\title{
Confecção de uma Fotonovela como Estratégia de Educação em Saúde: Relato de Experiência
}

\author{
Talizin, Elisabete Venturini; Cres, Marli Rosangela; Lannes, Milene Morais \\ Centro Universitário Adventista de São Paulo — bete.talizin@ig.com.br
}

As Doenças Crônicas Não Transmissíveis (DCNT) são uma das principais causas de morte no mundo e estão diretamente relacionadas ao estilo de vida do século XXI que é caracterizado pelo tabagismo, dieta insalubre, sedentarismo e uso abusivo do álcool. Além de incentivar a prevenção das DCNT, deve-se proporcionar um cuidado integral e humanizado aos portadores das mesmas. Muitos portadores de DCNT tem dificuldade em aderir ao tratamento proposto, tanto medicamentoso como mudanças no estilo de vida. por outro lado, os profissionais de saúde ainda tratam os usuários de saúde como "pacientes", ou seja, passivos, apáticos, impõem tratamentos e mudanças de estilo de vida que não são compreendidos pelos mesmos. É importante elaborar estratégias de educação em saúde que visem alterar essas situações. o objetivo desse trabalho foi confeccionar uma fotonovela como estratégia para educação em saúde. Esse trabalho foi realizado por duas enfermeiras e uma nutricionista, durante uma das disciplinas do mestrado profissional em Promoção de saúde no segundo semestre de 2013. a Fotonovela é caracterizada por um texto sob a forma de diálogos travados por personagens fotografados. Optou-se em confeccionar uma fotonovela, por ser uma estratégia de caráter lúdico, que pode contribuir para a educação em saúde, pois apresenta uma história do cotidiano, contém imagens e linguagem acessível. o objetivo da fotonovela não é simplesmente oferecer informações sobre o tratamento de DCNT, mas conduzir os leitores a reflexões e discussões, tanto os usuários de saúde como os profissionais e estudantes da área da saúde. o roteiro da fotonovela foi elaborado pelas autoras a partir das experiências como profissionais de saúde. Os atores foram familiares de uma das autoras e as próprias autoras. Foi criada uma história sobre um casal na faixa etária dos 40 anos, denominado "Casal sem sal e sem açúcar", que possuía Hipertensão Arterial e Diabetes Mellitus. a história se passa no ambiente doméstico e em um consultório de uma Unidade Básica de Saúde. Foram ilustradas algumas situações do cotidiano do casal que mostram as dificuldades em relação à adesão ao tratamento, tanto medicamentoso como mudanças no estilo de vida, a percepção da doença, a necessidade de apoio emocional e comunicação com os profissionais de saúde. na história foi proposta a atuação de uma equipe interdisciplinar que pratica a escuta sensível e valoriza a participação do usuário de saúde em seu tratamento. a fotonovela foi impressa em papel fotográfico colorido, tamanho A4 e contém 5 páginas. Os profissionais de saúde necessitam buscar e criar novas estratégias para a educação em saúde, trabalhar interdisciplinarmente, respeitar e valorizar os usuários de saúde.

Talizin, Elisabete Venturini; Cres, Marli Rosangela; Lannes, Milene Morais. Confecção de uma Fotonovela como Estratégia de Educação em Saúde: Relato de Experiência. In: Anais do Congresso Internacional de Humanidades \& Humanização em Saúde [= Blucher Medical Proceedings, num.2, vol.1]. São Paulo: Editora Blucher, 2014. ISSN 2357-7282

DOI 10.5151/medpro-cihhs-10273 